\title{
Formação continuada de professores, desenvolvimento profissional e conhecimento matemático na Educação Infantil
}

\section{Continuing teacher education, professional development and mathematical knowledge in Childhood Education}

\author{
Denise França Stehling \\ Keli Cristina Conti
}

\begin{abstract}
Resumo: 0 artigo busca apresentar os resultados de uma pesquisa desenvolvida no âmbito de um mestrado profissional em Educação, de uma universidade federal brasileira. A partir da pesquisa, desenvolvida numa abordagem qualitativa, destacamos aqui algumas reflexões sobre a formação continuada de professores, o desenvolvimento profissional e o conhecimento matemático na Educação Infantil. Nessa perspectiva, com o objetivo de evidenciarmos os saberes e conhecimentos matemáticos e metodológicos mobilizados, reconhecidos e ressignificados por professoras quando se reúnem num grupo de estudos, optamos por trazer os registros das práticas envolvendo Grandezas e Medidas. O plano de trabalho de campo e os instrumentos de registros de informações compreenderam a formação do grupo de professoras, aplicação de questionários em alguns momentos, encontros periódicos de formação, discussão, planejamento e registro. Analisamos que os saberes e conhecimentos matemáticos e metodológicos foram mobilizados, e outras aprendizagens como conhecimento curricular, durante a constituição e continuidade do grupo de estudos.
\end{abstract}

Palavras-chave: Educação Matemática. Formação continuada de professores. Desenvolvimento profissional. Educação Infantil. \begin{abstract}
professional master's degree in Education, from a Brazilian federal university. From the research, developed in a qualitative approach, we highlight here some reflections on the continuing education of teachers, professional development and mathematical knowledge in Early Childhood Education. And in this perspective, in order to highlight the mathematical and methodological knowledge and knowledge mobilized, recognized and re-signified by teachers when there is a study group, we chose to bring the records of the study practices Quantities and Measures. The field work plan and the information recording instruments include the formation of the group of teachers, the application of questionnaires in some moments, the periodic meetings of training, discussion, planning and registration. Analyze that the mathematical and methodological knowledge and knowledge were mobilized, and as other learnings such as curricular knowledge, during the constitution and continuity of the study group.
\end{abstract}

Abstract: The article seeks to present the results of a research developed within the scope of a

Denise França Stehling Mestre em Educação e Docência. Professora da Secretaria Municipal de Educação de Belo Horizonte. Minas Gerais, Brasil. (iD) orcid.org/0000-0001-9977-5575 $\bowtie$ dfstehling@gmail.com Keli Cristina Conti Doutora em Educação. Professora do Mestrado Profissional em Educação e Docência da Universidade Federal de Minas Gerais (UFMG). Minas Gerais, Brasil. (iD) orcid.org/0000-0001-5662-2923 $\bowtie$ keli.conti@gmail.com

Recebido em 28/05/2020 Aceito em 20/07/2020 Publicado em 27/07/2020

Keywords: Mathematics Education. Teacher training. Professional development. Childhood education. 


\section{Introdução}

Compreendemos que as preocupações com a abordagem de conhecimentos matemáticos na Educação Infantil são cada vez mais frequentes e é necessário entender que para os docentes desenvolverem suas atividades, é imprescindível um conjunto de conhecimentos que "formam uma espécie de reservatório, no qual o professor se abastece para responder as exigências específicas de sua situação concreta de ensino" (GAUTHIER et al., 2006, p. 28). Esses conhecimentos ligados ao fazer pedagógico constituem um desafio à formação docente, que formam os saberes que são mobilizados pelo professor em sua prática pedagógica.

Mas será que as formações continuadas atuais, muitas vezes pautadas por meio de portarias, têm acompanhado as demandas das instituições de Educação Infantil ao ponto de ressignificarem as práticas dos professores?

Para que isso ocorra é necessário que a prática pedagógica envolva formação qualificada e intencional. As mudanças na educação dependem de muitos fatores como educadores dispostos a estudar, curiosos, entusiasmados, com uma criatividade didática, que queiram investigar em um contexto colaborativo, como é fazer Matemática na Educação Infantil. De acordo com o Referencial Curricular Nacional para a Educação Infantil — RCNEI,

fazer matemática é expor ideias próprias, escutar as dos outros, formular e comunicar procedimentos de resolução de problemas, confrontar, argumentar e procurar validar seu ponto de vista, antecipar resultados de experiências não realizadas, aceitar erros, buscar dados que faltam para resolver problemas, entre outras coisas (BRASIL, 1998, p. 207).

Ao refletir e sistematizar sua prática, sabe-se que os professores produzem e renovam seus saberes e conhecimentos. Pesquisadores como Azevedo (2012), Conti (2015), Fiorentini e Lorenzato (2012), Imbernón (2010) e Nacarato (2008) vêm dando importância aos grupos de estudos envolvendo professores, pois esses contribuem com aprendizagens, saberes ou conhecimentos das experiências e os professores são estimulados a aprender com a reflexão, com a fala, bem como estimulados a analisar situações problemáticas e a elaborarem seus registros ou textos.

Nesse sentido, a pesquisa aqui descrita, fruto de um Mestrado Profissional (STEHLING, 2018), propôs a formação de um grupo de estudos para não só descrever situações problemáticas observadas no cotidiano das instituições, mas para ressignificar tais situações, buscando criar espaços de reflexão, de pesquisa e de inovação nas estratégias de aprendizagem referente ao 
conhecimento matemático na Educação Infantil, envolvendo números e sistema de numeração, espaço e forma, e grandezas e medidas ${ }^{1}$.

Para este artigo selecionamos, a partir da pesquisa, dois objetivos: destacar algumas reflexões sobre a formação continuada de professores, o desenvolvimento profissional e 0 conhecimento matemático na Educação Infantil, por meio de um referencial teórico; e evidenciarmos os saberes e conhecimentos matemáticos e metodológicos mobilizados, reconhecidos e ressignificados por professoras quando se reúnem num grupo de estudos, por meio dos registros das práticas envolvendo Grandezas e Medidas e o que as participantes chamaram de "despertar para outras coisas"2, que foi discutida num dos encontros do grupo, destacando os fazeres práticos dos professores. No que tange as Grandezas e Medidas, o foco foi, de acordo o documento Referencial Curricular Nacional para a Educação Infantil, a "Exploração de diferentes procedimentos para comparar grandezas; Introdução às noções de medida de comprimento [...] pela utilização de unidades convencionais e não convencionais" (BRASIL, 1998, p. 225).

Durante a realização do trabalho de campo da pesquisa, foram enviados convites para vinte e sete instituições de Educação Infantil da Rede Municipal de Educação de Belo Horizonte. Aceitaram o convite e participaram da pesquisa oito professoras que atuavam com crianças de 4 e 5 anos. Os encontros do grupo, que almejou ser colaborativo, aconteceram de outubro a dezembro de 2017, totalizando sete encontros com duração de três horas cada um, na sala de reuniões de uma Unidade Municipal de Educação Infantil, que se localizava dentro do campus da Universidade Federal de Minas Gerais. O cronograma com as datas dos encontros foi elaborado a posteriori, juntamente com as professoras participantes, sendo coletivo também o levantamento das temáticas a serem estudadas em cada encontro e que serão mais explorados na sessão Caminhos da Pesquisa.

\footnotetext{
${ }^{1}$ Ao desenvolvermos o trabalho de campo da pesquisa, nos baseamos no Referencial Curricular Nacional para Educação Infantil (BRASIL, 1998) e nas temáticas trazidas por este documento. A BNCC (BRASIL, 2017) estava em fase de implantação, não configurando como documento oficial do governo federal e, portanto, não foi discutida na ocasião.

2 Para cada encontro do trabalho de campo, foram escolhidos nomes a partir de algo que chamou a atenção das participantes ou algo presente em suas falas. Essa expressão presente na fala de uma professora, busca refletir como a proposta de um grupo de estudos possibilitou que "despertassem" para além do que faziam, pudessem visualizar outras possibilidades para o ensino e a aprendizagem de Matemática na Educação Infantil.
} 


\section{Formação continuada de professores da Educação Infantil}

No Brasil, a partir de 1990, de acordo com Leite (2010), o curso de Pedagogia foi se constituindo como o principal lugar de formação inicial de professores para atuar nos Anos Iniciais do Ensino Fundamental e na docência da Educação Infantil. Atualmente, conforme as Diretrizes Curriculares Nacionais do Curso de Pedagogia - Resolução n. 01 CNE/CP, de maio de 2006 compete ao curso de Licenciatura em Pedagogia a formação dos profissionais que vão atuar nos Anos Iniciais do Ensino Fundamental e Educação Infantil. Esse curso tem duração média de 4 anos e, nos primeiros semestres, oferece disciplinas como História da Educação, Sociologia, Psicologia e, ao longo do curso, disciplinas que visam contribuir com a prática da sala de aula, como Alfabetização e Metodologias para o ensino de Língua Portuguesa, Matemática, História, Geografia, Ciências, Educação Física, Artes. O curso tem, ainda, disciplinas que visam apoiar 0 trabalho do professor no planejamento, avaliação e a gestão educacional, além de ter estágio supervisionado obrigatório. De acordo com Leite (2010, p. 584), "dificilmente, uma instituição de ensino superior poderá possibilitar uma formação docente capaz de garantir um conjunto de conhecimentos realmente relevantes e essenciais à formação docente".

Sob muitos aspectos, a carência em formação inicial docente tem um impacto sobre os professores, o que vemos na Educação Infantil, muitas vezes, é um trabalho pautado em revistas, guias, blogs e manuais em que se repassa atividades a serem reproduzidas e copiadas sem análise e reflexão docente. Alguns formadores de professores como Imbernón (2010, p. 39) vêm defendendo a ideia de que "de forma paradoxal, há muita formação e pouca mudança", pois há práticas formativas com características transmissoras e uniformes, não atendendo demandas específicas dos inúmeros contextos existentes em cada instituição de Educação Infantil.

Nesse sentido, se a formação inicial é deficitária, investir em formação continuada deveria resolver o problema dessa carência, mas não resolve, pois, a formação continuada não costuma causar um grande impacto na prática pedagógica. Então, o que o contexto atual demanda? Outra perspectiva de formação é possível?

Esse pode ser um bom momento para traçar, ou pelo menos para imaginar, um presente desejável e uma nova formação continuada para professores, tendo enfoque aqui nesse estudo para o conhecimento matemático na Educação Infantil. Teóricos apontam que os cursos padronizados podem servir para gerar processos de reflexão, mas se não forem acompanhados de mudanças contextuais, como promoções na carreira, não teremos um profissional inovador. 
Segundo Imbernón (2010, p. 47),

a formação continuada deveria apoiar, criar e potencializar uma reflexão real dos sujeitos sobre sua prática docente nas instituições educacionais e em outras instituições, de modo que Ihes permitisse examinar suas teorias implícitas, seus esquemas de funcionamento, suas atitudes, etc, estabelecendo de forma firme um processo constante de autoavaliação do que se faz e por que se faz.

Podemos ter a formação potencializada, mais ligada à prática e que incentive a autonomia dos professores na gestão de sua própria formação, tendo como ponto de partida um professor protagonista ativo da sua prática formativa e continuada. Trata-se de abandonar o conceito tradicional que supõe organizar e reconstruir a prática dos professores, a mudança no sentido de comprometerem-se com a formação de um sujeito que tenha capacidade de análise e de reflexão crítica, de decisão racional, de avaliação de processos e de reformulação de projetos em seu contexto e com seus colegas. Tudo isso, por meio de grupos de estudos entre os que conhecem e vivem as reais condições do trabalho dentro das instituições. Trata-se de retirar o docente da afonia a que foi submetido, dando-lhe voz.

Assumimos neste estudo a perspectiva de colaboração defendida como potencializadora da formação continuada, pensando na proposta de trabalho de um grupo colaborativo, assumindo, como Fiorentini (2006), que na colaboração

todos trabalham conjuntamente (co-laboram) e se apoiam mutuamente, visando atingir objetivos comuns negociados pelo coletivo do grupo. Na colaboração, as relações, portanto, tendem a ser não-hierárquicas, havendo liderança compartilhada $\mathrm{e}$ corresponsabilidade pela condução das ações (p. 52).

Acreditamos que a formação continuada em contexto colaborativo pode criar possibilidades e potencial baseados nas atitudes interacionistas e dialógicas entre os professores e pesquisadores. Também pode articular conhecimentos teóricos e práticos que afirmam a intencionalidade do ato educativo e principalmente o protagonismo de práticas de ensino entre professores. A partir de Fiorentini (2006), sintetizamos o que poderíamos conceber por um grupo de trabalho colaborativo em que:

- a participação é voluntária e todos desejam crescer profissionalmente;

- há um desejo de compartilhar saberes e experiências;

- há momentos, durante os encontros, para bate-papo informal, confraternização e comentários da prática escolar; 
- os participantes sentem-se à vontade para expressar o que pensam e sentem;

- não existe uma verdade ou orientação única para as atividades, podendo haver diferentes pontos de vista dos participantes;

- as tarefas e atividades dos encontros são planejadas de modo a garantir que o tempo dos encontros seja o mais produtivo possivel;

- a confiança e o respeito mútuo são essenciais ao bom relacionamento do grupo;

- os participantes negociam metas e objetivos comuns, corresponsabilizando-se para alcançá-los;

- os participantes compartilham significados acerca do que estão fazendo e aprendendo e o que isso significa para suas vidas e prática profissional;

- os participantes têm oportunidade de produzir e sistematizar conhecimentos sobre a prática de cada um, resultando a produção de textos escritos, os quais podem ser publicados e socializados aos demais professores;

- há reciprocidade de aprendizagem, ou seja, todos os participantes aprendem uns com os outros; todos se constituem em aprendizes e "ensinantes".

A perspectiva de formação docente por meio de grupo de estudos em contexto colaborativo incita o debate sobre a necessidade de escutar as situações cotidianas do professor, de permitir a livre expressão sobre seus conhecimentos, medos, angústias, proporcionando novas aprendizagens por meio de momentos de reflexão e de partilhas colaborativas e, consequentemente, seu desenvolvimento profissional. Importante destacar que a diferença reside no fato de que todos os participantes de um grupo colaborativo podem assumir um protagonismo no grupo, não se reduzindo a auxiliares, mas sujeitos ativos que produzem conhecimentos, aprendem e ensinam uns aos outros.

Com os princípios apontados por Imbernón (2010), apoiados em criar e potencializar a reflexão dos professores e um processo contínuo de autoreflexão em que se reflita sobre o que se faz e por que se faz, planejamos o trabalho de campo, com enfoque à estratégia metodológica de um contexto colaborativo (FIORENTINI, 2006) ao propormos a constituição de um grupo de estudos envolvendo a pesquisadora e professoras que atuavam na Educação Infantil. Ao abordarmos formação docente proporcionando novas aprendizagens continuadamente, inserimos no tema desenvolvimento profissional ou profissionalidade docente, tema da próxima seção. 


\title{
3 Formação e desenvolvimento profissional
}

Um dos grandes desafios dos programas de formação docente reside no fato de motivar os professores a aprender. Abordar o tema desenvolvimento profissional significa buscar compreender a vida pessoal e profissional do professor, bem como as políticas e os contextos das instituições em que realizam sua atividade docente (DAY, 2001). Como já foi dito, não podemos analisar a formação continuada sem abordar as condições de trabalho docente e o sujeito professor como investigador que aprende com suas próprias práticas. Nesta lógica, compreendese que o desenvolvimento profissional constitui um assunto crucial dentro da análise sobre formação docente. Conforme Day (2001, p. 18),

\begin{abstract}
0 conceito de desenvolvimento profissional inclui a aprendizagem eminentemente pessoal, sem qualquer tipo de orientação, a partir da experiência (através da qual a maioria dos professores aprendem a sobreviver, a desenvolver competências e a crescer profissionalmente nas salas de aula e nas escolas), quer as oportunidades informais de desenvolvimento profissional vividas na escola, quer ainda as mais formais oportunidades de aprendizagem "acelerada", disponíveis através da atividade de treino e de formação contínua, interna e externamente organizadas.
\end{abstract}

Podemos, a partir desse conceito, levantar questões sobre: Como, quando e em que circunstâncias os professores aprendem? O conceito de desenvolvimento profissional envolve 0 fazer docente na própria experiência nas instituições, bem como o saber adquirido nas universidades ou cursos de formação. Esse estudo concebe ainda que a formação docente precisa se basear nas situações problemáticas das práticas pedagógicas, realizadas principalmente na própria instituição que também deve repensar seus projetos e suas práticas.

O ideal seria que as propostas de formação continuada repensassem e ressignificassem o desenvolvimento profissional docente a partir de um conjunto de conhecimentos essenciais e relevantes, evitando a mera transmissão do conhecimento, mas compreendendo a importância da constituição de um sujeito professor reflexivo quanto à sua própria prática.

Nessa abordagem, visamos encontrar alternativas de aprendizagem colaborativa. Não significa encontrar uma solução para um processo que é tão complexo, mas propor grupos de estudos para aprendizagem de todos os membros de uma instituição de Educação Infantil, pode ser um caminho motivador que leve professores a aprender coletiva ou individualmente. Acreditamos que professores mais confiantes e mais comprometidos com a sua própria aprendizagem, transformam a qualidade da educação, conforme defende Day (2001, p. 20-21): 


\begin{abstract}
O desenvolvimento profissional envolve todas as experiências espontâneas de aprendizagem e as atividades conscientemente planificadas, realizadas para benefício, direto ou indireto, do indivíduo, do grupo ou da escola e que contribuem, através destes, para a qualidade da educação na sala de aula. É o processo através do qual os professores, enquanto agentes de mudança, reveem, renovam e ampliam, individual ou coletivamente, o seu compromisso com os propósitos morais do ensino, adquirem e desenvolvem, de forma crítica, juntamente com as crianças, jovens e colegas, o conhecimento, as destrezas e a inteligência emocional, essenciais para uma reflexão, planificação e prática profissionais eficazes, em cada uma das fases das suas vidas profissionais.
\end{abstract}

Nesse sentido, um ensino de qualidade implica o trabalho do ser professor envolvendo tarefas com características emocionais imbuídas de prazer, criatividade, alegria ou dúvidas. Também envolve o pensar profissionalmente enfatizando a perspectiva reflexiva das ações docentes. Estudos como o de Day (2001) defendem que o propósito central do desenvolvimento profissional é possibilitar a formação do professor como aprendente. Essa perspectiva vai contra a transmissão de conteúdos que, na maioria das vezes, desconsidera os contextos em que os professores trabalham e onde as vivências e experiências acontecem.

Entendemos que o processo de professores se tornarem investigadores é complexo e envolve diferentes demandas e intervenções externas. A investigação docente depende não só do desejo dos professores de se envolverem na reflexão, conforme cita Day (2001), mas também da vontade da instituição e daqueles que participam indiretamente do projeto pedagógico como as secretarias e órgãos governamentais de educação.

Nem sempre as instituições estimulam os professores a relatarem suas práticas ensinando uns aos outros. Sabemos que os professores possuem experiências positivas com relação às suas práticas pedagógicas e querem explicitá-las como um saber prático pessoal. Nesse sentido, entendemos que a possibilidade de um trabalho colaborativo estimula a interação contínua por meio da oportunidade de os professores discutir e refletir suas práticas pedagógicas e com destaque aqui para o conhecimento matemático, tema da próxima seção, para posteriormente descrevermos o percurso da pesquisa.

\title{
4 Conhecimento matemático e a Educação Infantil
}

De acordo com o Referencial Curricular Nacional para a Educação Infantil (RCNEI), "as crianças, desde o nascimento, estão imersas em um universo do qual os conhecimentos matemáticos são parte integrante" (BRASIL, 1998, p. 207). Entendemos que o professor pode 
fazer com que a criança, partindo de suas vivências e de seu conhecimento prévio, avance no sentido de construir e reconstruir novos conhecimentos. Uma prática pedagógica eficiente seria aquela que provoca mudança, permitindo que as crianças construam saberes e não apenas realizem instruções mecanizadas repassadas pelos professores.

Conforme texto introdutório do RCNEI, o âmbito Conhecimento de mundo, contém seis documentos referentes aos eixos de trabalho orientados para a construção das diferentes linguagens pelas crianças e para as relações que estabelecem com os objetos de conhecimento: movimento, música, artes visuais, linguagem oral e escrita, natureza e sociedade e Matemática. Embora tenhamos um conjunto de linguagens, nosso destaque nesse estudo será apenas para a Matemática.

A linguagem matemática foi apresentada no RCNEI com os seguintes tópicos: i) Introdução; ii) Presença da Matemática na Educação Infantil: ideias práticas e correntes; iii) A criança e a Matemática - apresentados em três blocos: (1) Números e sistema de numeração, (2) Grandezas e medidas e (3) Espaço e forma; e vi) Orientações gerais para o professor: jogos e brincadeiras, organização do tempo, observação, registro e avaliaçãoformativa.

Autores como Lorenzato (2011) apontam ainda que o trabalho com noções matemáticas na Educação Infantil traz resultados no desenvolvimento e estímulo aos processos mentais. Crianças aprendem observando, explorando e enfrentando situações-problema relacionadas às ideias e processos de natureza matemática como contar, localizar, medir, desenhar, jogar e explicar.

Em relação à Educação Infantil e ao conhecimento matemático, acreditamos que nos primeiros dias de vivências e experiências na Educação Infantil, é imprescindível que o professor investigue o que as crianças compreendem sobre números, espaço e medidas. Nesse contexto, Lorenzato (2011) afirma que "toda criança chega à pré-escola com alguns conhecimentos e habilidades no plano físico, intelectual e sócio afetivo, fruto de sua história de vida. Essa bagagem, que difere de criança para criança, precisa ser identificada pelo professor" (p. 24).

Nessa perspectiva, 0 autor sugere que a base da proposta de um trabalho matemático se sustente em três campos: aproveitar os conhecimentos e habilidades de que as crianças são portadoras; explorar os três campos matemáticos (espacial, numérico e medidas); e começar 0 trabalho pelas noções.

Lorenzato (2011) sugere que essas noções devem ser revisadas ou introduzidas 
verbalmente e por meio de diversas situações, visando trabalhar com materiais manipulativos, desenhos e histórias. 0 autor afirma que 0 trabalho deve se sustentar nos três campos citados acima e iniciar nos ambientes de práticas pedagógicas na Educação Infantil, a partir das noções que ele organizou em três grupos conforme Quadro 1.

Quadro 1: Noções matemáticas

\begin{tabular}{|c|c|c|}
\hline \multicolumn{3}{|c|}{ NOÇÕES MATEMÁTICAS } \\
\hline grande/pequeno & mais/menos & aberto/fechado \\
maior/menor & muito/pouco & em cima/embaixo \\
grosso/fino & igual/diferente & direita/esquerda \\
curto/comprido & dentro/fora & primeiro/último/entre \\
alto/baixo & começo/meio/fim & na frente/atrás/ao lado \\
largo/estreito & antes/agora/depois & para frente/atrás/ao lado \\
perto/longe & cedo/tarde & para a direita/para a \\
leve/pesado & dia/noite & esquerda \\
vazio/cheio & ontem/hoje/amanhã & para cima/para baixo \\
& devagar/depressa & ganhar/perder \\
& & aumentar/diminuir \\
\hline
\end{tabular}

Fonte: Lorenzato (2011, p. 24)

Quanto aos resultados, espera-se que a criança se interesse cada vez mais pela investigação e exploração matemática em três campos aparentemente independentes: o espacial, das formas, que apoiará o estudo da geometria; o numérico, das quantidades, que apoiará 0 estudo da aritmética; e o das medidas, que desempenhará a função de integrar a geometria com a aritmética. Ao se apropriarem de um modo de organização, mesmo que induzido pelos adultos, as crianças estão aceitando e incorporando princípios de naturezalógica.

Seja qual for a noção ou o campo matemático (espaço, número, medida) que estiver sendo trabalhado, haverá sempre uma relação direta com um dos conceitos físico-matemáticos seguintes, conforme Quadro 2.

Quadro 2: Conceitos físicos matemáticos

\begin{tabular}{|c|c|c|c|}
\hline \multicolumn{4}{|c|}{ CONCEITOS FísICOS MATEMÁTICOS } \\
\hline tamanho & quantidade & posição & volume \\
lugar & número & medição & comprimento \\
distância & capacidade & operação & massa \\
forma & tempo & direção & \\
\hline
\end{tabular}

Fonte: Lorenzato $(2011$, p. 25$)$

Lorenzato (2011) ainda defende a necessidade de manter o trabalho com as noções básicas da aritmética. Ele ressalta que, para o professor ter sucesso na organização de situações 
que propiciem a exploração matemática pelas crianças, é fundamental que ele conheça os sete processos mentais básicos para aprendizagem do conceito de número:

- Correspondência - é o ato de estabelecer a relação um aum.

- Comparação - é o ato de estabelecer diferenças ou semelhanças.

- Classificação - é o ato de separar em categorias de acordo com semelhanças ou diferenças.

- Sequenciação - é o ato de fazer suceder a cada elemento um outro sem considerar a ordem entre eles.

- Seriação - é o ato de ordenar uma sequência segundo um critério.

- Inclusão - é o ato de fazer abranger um conjunto por outro.

- Conservação - é o ato de perceber que quantidade não depende da arrumação, forma ou posição.

Esses processos têm o objetivo de dar a conhecer o nível que as crianças se encontram na aquisição de determinados conceitos matemáticos e nunca foram pensados como tarefas a serem realizadas nas instituições de Educação Infantil. A observação do desenvolvimento desses processos é útil para a orientação das professoras no sentido de proporem questionamentos, vivências e experiências adequadas para que as crianças entrem em conflito com conhecimentos que possuem, visto que aprender Matemática é construir significados e sentidos lógicos. Lorenzato (2011, p. 25) afirma ainda que "sem o domínio desses processos, as crianças poderão até dar respostas corretas, segundo a expectativa e a lógica dos adultos, mas certamente sem significado ou compreensão para elas".

Nesse instante, o olhar do professor pode ser crucial e desempenhar um papel importante, pois para construir o conceito de número, além de aprender a contar, as crianças devem ser estimuladas a seriar, estabelecer correspondência, classificar, nomear, simbolizar e agrupar. $\mathrm{Na}$ maioria das vezes, essas ações aparecem espontaneamente em vivências cotidianas ou em brincadeiras, pois a Matemática está diretamente envolvida em atividades humanas.

Nessa perspectiva, a prática pedagógica é intencional, a atividade desenvolvida pela professora caracteriza-se por alcançar um fim, assumindo papel de mediadora entre as crianças e as práticas pedagógicas propostas. Daí decorre uma característica fundamental da atividade 
docente: a intencionalidade planejada e criativa, pressupondo uma consciência e clareza nas ações docentes.

A partir deste entendimento, o estudo em questão acredita na necessidade da criação de espaços onde as professoras possam desenvolver uma habilidade contínua de reflexão da prática pedagógica identificando e superando situações contraditórias e reprodutoras de "modismos pedagógicos".

Finalizamos esta seção destacando que é nesse contexto também que os problemas e as inquietações aparecem sobre o trabalho e a formação do professor da Educação Infantil, mas que não será discutido aqui. Passamos agora a apresentar as questões metodológicas da pesquisa.

\section{Caminhos da pesquisa}

A estratégia metodológica delineada nessa pesquisa foi o processo colaborativo, com envolvimento da pesquisadora e das professoras participantes buscando reflexão e discussão sobre as práticas pedagógicas e o conhecimento matemático e que será mais explorado a seguir. Essa pesquisa foi desenvolvida com abordagem qualitativa que, de acordo com Bogdan e Biklen (1994), possui cinco características:

1) $\mathrm{Na}$ investigação qualitativa a fonte direta de dados é o ambiente natural, constituindo o investigador 0 instrumento principal;

2) A investigação qualitativa é descritiva;

3) Os investigadores qualitativos interessam-se mais pelo processo do que simplesmente pelos resultados ou produtos;

4) Os investigadores qualitativos tendem a analisar os seus dados de forma produtiva;

5) O significado é de importância vital na abordagem qualitativa (BOGDAN; BIKLEN, 1994, p. 47-50).

Nesse sentido, foi proposta a seguinte questão de investigação: Quais os saberes e conhecimentos matemáticos e metodológicos mobilizados, reconhecidos e ressignificados por professores da Educação Infantil, da Rede Municipal de Ensino de Belo Horizonte, quando se reúnem em grupo de estudos?

Tivemos como objetivo analisar as práticas pedagógicas relatadas por professores em um contexto de grupo de estudos, buscando entender situações problemáticas dos professores no que tange ao conhecimento matemático na Educação Infantil. Conforme Imbernón (2010, p. 65), 
isso supõe uma formação voltada para um processo que provoca uma reflexão baseada na participação, com contribuição pessoal, não rigidez, motivação, metas comuns, normas claras, coordenação, autoavaliação, e mediante uma metodologia de formação centrada em casos, trocas, debates, leituras, trabalho em grupo, incidentes críticos, situações problemáticas, etc.

Neste artigo, nosso destaque será para reflexões sobre a formação continuada de professores, o desenvolvimento profissional e o conhecimento matemático na Educação Infantil. Nessa perspectiva, de acordo com o objetivo, optamos por trazer os registros das práticas envolvendo Grandezas e Medidas e o que as participantes chamaram de "despertar para outras coisas", que foi discutida num dos encontros do grupo, destacando também os fazeres práticos das professoras participantes, ou seja, optamos por destacar algo que chamou a atenção das professoras e também apresentando o professor num papel de destaque na geração de conhecimento sobre a prática (COCHRAN-SMITH e LYTLE,1999).

A ideia de formação de um grupo de estudos parte do princípio de experimentar, viver e construir coletivamente o saber e o conhecimento, interessando mais os processos do que simplesmente os resultados ou produtos.

Antes de iniciar esta pesquisa, de acordo com a legislação vigente, o projeto foi submetido à aprovação junto ao Comitê de Pesquisa em Seres Humanos do Ministério da Saúde, pelo Sistema Nacional de Informações sobre Ética em Pesquisa envolvendo Seres Humanos (SISNEP) ${ }^{3}$. A partir de sua aprovação, demos início ao movimento de criação do grupo propondo que em cada encontro os professores relatassem o que acontece em suas práticas pedagógicas, o que fazem, o que funciona, o que não funciona, compartilhando, conforme cita Imbernón (2010, p. 68), "as alegrias e as penas que surgem no difícil processo de ensinar e aprender". A seguir, apresentaremos as atividades de campo e os instrumentos de registros de informações:

- Formação do grupo de professores que aceitaram fazer parte da proposta, após recebimento do ofício e do convite por e-mail;

- Ficha de identificação com os interessados: primeira aproximação com os participantes da pesquisa, oferecendo dados para a realização e direcionamento do trabalho docente e da pesquisa, de acordo com os objetivos que pretendíamos alcançar;

- Encontros periódicos de formação, discussão, planejamento, estudo e registro com todos

\footnotetext{
${ }^{3}$ A pesquisa foi aprovada pelo COEP-UFMG com Certificado de Apresentação para Apreciação Ética (CAAE) 7708
} 3517.9.0000.5149. 
os participantes;

- Elaboração, por parte da pesquisadora, de um diário de campo para relatar e registrar temporalmente a experiência vivida;

- Registros de áudio e/ou vídeo das atividades desenvolvidas no grupo;

- Relatos escritos (caderno ou portfólio) a serem compartilhados com outros professores, como produto educacional decorrente da pesquisa.

Ao finalizarmos o projeto de pesquisa, iniciou-se um diálogo com a Secretaria Municipal de Educação e após sua autorização, deu-se o envio do convite para vinte e sete instituições de Educação Infantil da Rede parceira (creches conveniadas) e Rede própria: Escola Municipal de Educação Infantil (EMEI) e Unidade Municipal de Educação Infantil (UMEI) de ensino de Belo Horizonte.

A escolha das instituições se deu de forma aleatória utilizando uma listagem pública geral disponível no portal da Prefeitura de Belo Horizonte contendo 127 Unidades Municipais de Educação Infantil (UMEI), 13 Escolas Municipais de Educação Infantil (EMEI) e 195 creches conveniadas, que compõem a rede parceira, conforme informação do portal Prefeitura de Belo Horizonte, acessado em agosto de 2017.

O único critério estabelecido foi o envio de convite para três instituições de cada regional da cidade: Barreiro, Centro Sul, Leste, Nordeste, Noroeste, Norte, Oeste, Pampulha e Venda Nova, sendo que o convite foi destinado, prioritariamente, para professores que estavam na regência das turmas de quatro e cinco anos.

Após algumas confirmações e reenvio do e-mail, foram registradas onze professoras interessadas em participar da pesquisa. Importante destacar que a participação do grupo de estudos ocorreu em seus horários de trabalho, e a adesão foi livre. Foram propostos sete encontros com três horas de duração cada um, com frequência periódica semanal e acontecendo no turno da tarde, nos meses de outubro, novembro e dezembro de 2017. Não recebemos e-mail de confirmação de presença das instituições convidadas que fazem parte das regionais Leste, Norte e Oeste.

Importante destacar que o papel da pesquisadora foi implementar, ou seja, constituir um processo de mediação que possibilitasse a discussão e o desenvolvimento dos conhecimentos matemáticos, problematizando situações por meio de questões e discussões teóricas sobre as 
práticas pedagógicas relatadas pelas professoras participantes. Outra estratégia abordada no percurso da pesquisa foi a leitura de textos para a compreensão e superação das dificuldades das práticas pedagógicas relatadas, despertando nas participantes um motivo para modificarem sua postura pedagógica.

No primeiro encontro, em 19 de outubro de 2017, das onze professoras que mostraram interesse por e-mail em participar da pesquisa, nove compareceram. A partir desta seção usaremos o termo "professora" para referirmos às participantes da pesquisa, por visualizarmos como perfil que é do campo da Educação Infantil encontrar mais docentes do gênero feminino contrapondo ao masculino, demarcando o gênero feminino como maioria entre os docentes. Por isso, torna-se importante analisar e buscar compreender a função e o papel social e político que a professora da Educação Infantil desempenha em nossa sociedade.

O grupo de estudos iniciou com nove professoras presentes no primeiro encontro e finalizou com oito participantes. Os encontros foram realizados semanalmente nos meses de outubro, novembro e dezembro, como já citado e confirmados a posteriori juntamente com as professoras participantes, sendo coletivo também o levantamento das temáticas a serem estudadas em cada encontro. Não havia um planejamento previamente organizado; as temáticas eram demandadas pelas participantes do grupo, teorizadas e discutidas após as escolhas.

Nesse sentido, entendemos que a possibilidade de um trabalho colaborativo estimula a interação contínua por meio da oportunidade de os professores discutir e refletir suas práticas pedagógicas, o que vai contra a transmissão de conteúdos que, na maioria das vezes, desconsidera os contextos em que os professores trabalham e onde as vivências e experiências acontecem. A pesquisadora, juntamente com as participantes, organizavam ao final do encontro o que seria discutido no encontro seguinte e dividiam as responsabilidades, como por exemplo, quem se responsabilizaria pelo referencial teórico, quem faria os registros, quem compartilharia sua prática, o que seria trazido da escola.

Avaliamos que a questão do envolvimento das participantes do grupo de estudos apresentou uma das características de um grupo colaborativo, como o compromisso, esse compreendido como participação e envolvimento no grupo de estudos, diferentemente de apenas presença nos encontros. Pesquisadores como Azevedo (2012), Conti (2015), Fiorentini (2006), Imbernón (2010) e Nacarato (2008) vêm dando importância aos grupos de estudos envolvendo professores, pois esses tiram lições, aprendizagens, saberes ou conhecimentos das experiências 
quando incomodados a aprender com a reflexão, com a fala, bem como estimulados a analisar situações problemáticas e a elaborarem seus registros ou textos.

Ao longo dos encontros, foi construído um perfil das participantes (Quadro 3), com base no que foi declarado numa ficha de identificação 4 . Ao longo dos encontros, as participantes se deixam conhecer enquanto sujeito que ressignifica sua prática por meio de relatos orais compartilhados em um grupo de estudos.

Quadro 3: Perfil das professoras

\begin{tabular}{|c|c|c|c|c|}
\hline NOME & TURMA & $\begin{array}{r}\text { ANOS DE ATUAÇÃO NA } \\
\text { EDUCAÇÃO INFANTIL }\end{array}$ & IDADE & ESCOLARIDADE \\
\hline Adriana & 5 anos & 14 & 45 anos & Superior/Pedagogia \\
\hline Andriza & 4 anos & 18 & 40 anos & Ensino Médio \\
\hline Auremi & 5 anos & 5 & 44 anos & Superior \\
\hline Elisangela & 5 anos & 9 & 41 anos & Superior/Pedagogia \\
\hline Jane & 4 anos & 1 & 39 anos & Superior/Letras \\
\hline Lílian & 5 anos & 5 & 41 anos & Superior Normal \\
\hline Paula & Não & 6 & 53 anos & Superior/Pedagogia \\
\hline informado & 5 anos & 2 & 40 anos & Superior/Pedagogia \\
\hline
\end{tabular}

Fonte: Dados da pesquisa (2017).

Após ver e rever o material de áudio e vídeo produzido no trabalho de campo durante os encontros do grupo de estudos, visualizamos as possibilidades de análise, como indissociáveis em um processo de formação: o ser, o pensar, o saber e o fazer. Esses eixos partem da premissa de que a essência da formação docente não pode ser encontrada apenas no docente como sujeito (TARDIF, 2002).

Entendemos esses eixos circundando a vida de um professor, seja ele da Educação Infantil ou de qualquer outra etapa de ensino. Tentaremos descrever e analisar o antagonismo, ou seja, a complexa e paradoxal característica humana de sermos ao mesmo tempo ser e pensar e saber e fazer.

Para além dessa análise, vale ressaltar que o ser e pensar e o saber e fazer apareceram todo o tempo nos relatos realizados pelas participantes dessa pesquisa impactando diretamente

\footnotetext{
${ }^{4}$ As participantes autorizaram o uso do seu primeiro nome.
} 
nossas análises, sendo necessário a abordagem desses eixos.

Assim, em síntese, compreendemos o eixo ser no grupo, como a identidade, a forma de participação e o desejo. $O$ eixo pensar foi compreendido como exercício da reflexão em sua prática pedagógica. Entendemos que o saber docente acontece porque tem um pensar e um ser. 0 eixo saber foi compreendido nesse estudo como os saberes docentes próprios da Educação Infantil inserido no conhecimento matemático. Conforme Tardif (2002), o saber disciplinar constitui 0 conteúdo das matérias ensinadas na escola e isso nos desperta para a tarefa docente que não é apenas ensinar conteúdos, mas também é preciso saber bem os conteúdos, e não reduzir a prática docente ao puro ensino de conteúdo. Finalizando, o eixo fazer ficou definido neste estudo como ação docente na Educação Infantil, que tem por objetivo a linguagem matemática. Entendemos que 0 trabalho com as diferentes linguagens é fundamental na infância, das quais a linguagem matemática é o foco desse estudo. 0 eixo fazer está entendido ainda como mediação docente, suas intervenções, a organização da sala e a elaboração do planejamento das práticas pedagógicas.

Essa proposta de análise parte de uma demanda identificada, ao longo dos encontros do grupo de estudos, que indiretamente exige que as professoras ampliem cada vez mais seus conhecimentos sobre o ser humano nos primeiros anos de vida, envolvendo a compreensão sobre a criança, suas capacidades, necessidades e possibilidades.

Podemos expandir essa análise ponderando que a construção da identidade de professores e professoras da Educação Infantil constitui elementos centrais das políticas e práticas. Envolve ainda tanto a formação quanto as condições de trabalho, analisadas aqui como saber e fazer e nesse contexto de análise representa a mediação entre a teoria e a prática.

Observamos, por meio de algumas falas e manifestações que os eixos de análise sugeridos se interrelacionam num movimento circulante propiciando uma sinergia, que se apoia na subjetividade e individualidade do professor, mas também recebe influências do seu saber e do seu fazer. Esses eixos constroem juntos, a categoria que analisamos sobre a formação docente, dentro de uma proposta de grupo em contexto colaborativo.

A categoria a ser analisada na formação docente passaria pelos eixos na perspectiva de cada sujeito professor. Quem é esse professor? O que ele pensa? O que sabe? Então, o que ele realiza em suas práticas pedagógicas precisa ser analisado ao propormos uma formação docente. Isso parece óbvio, mas a novidade é a proposta de exploração das pluralidades circulantes em 
um processo de formação docente que acreditamos ser contínuo.

Podemos imaginar apontamentos surpreendentes na aplicação dessa hipótese: o estudo da circularidade infinita, contínua e dinâmica do processo de formação docente. Pensar processos formativos precisaria compreender o sujeito docente em suas múltiplas dimensões em busca de um desenvolvimento profissional de qualidade.

Depois do destaque para as reflexões sobre a formação continuada de professores, 0 desenvolvimento profissional e o conhecimento matemático na Educação Infantil, passamos a apresentar excertos do trabalho de campo da pesquisa, buscando destacar os eixos de análise.

\section{Despertando para outras coisas - o trabalho de campo}

Após realizados três encontros, nos quais foram discutidos o que as participantes já faziam e como faziam (primeiro encontro - intitulado posteriormente para a pesquisa como Para pensar a prática), sobre a medida de tempo e seus registros (segundo encontro - intitulado Tempo para ir mais devagar) e sobre quantidades e a construção do número (terceiro encontro - intitulado Tudo é conjunto).

Aqui são apresentados alguns excertos do encontro que ocorreu no dia 16 de novembro de 2017. Foi nosso quarto encontro e ele foi intitulado posteriormente para a pesquisa como Despertando para outras coisas, sendo iniciado com o relato da professora Jane, sobre Grandezas e Medidas ${ }^{5}$. Ela iniciou dizendo que conversou com algumas colegas da creche e descobriu que esse tema não era muito explorado em sua instituição. Relatou que conversou com as professoras das turmas de crianças de três anos, sondando como elas trabalhavam com as grandezas e as medidas. Suas colegas relataram que não trabalhavam com essas noções. A única forma utilizada em 2017, foi uma contação de história utilizando o livro Cachinhos de Ouro, de Ana Maria Machado. Elas confeccionaram e exploraram com as crianças caixinhas de tamanhos diferentes: pequeno, médio e grande - representando os ursos da história6.

Em sua turma de primeiro período, de crianças com quatro anos, a professora Jane

\footnotetext{
5 Segundo orientações do documento Referencial Curricular Nacional para a Educação Infantil, o bloco "Grandezas e Medidas", envolve: "Exploração de diferentes procedimentos para comparar grandezas; Introdução às noções de medida de comprimento, peso, volume e tempo, pela utilização de unidades convencionais e não convencionais; Marcação do tempo por meio de calendários; Experiências com dinheiro" (BRASIL, 1998, p. 225).

6 Provavelmente a abordagem era a de comparação da altura dos integrantes da família de ursos e dos objetos da casa da família.
} 
elaborou o Painel do crescimento, explorando as medidas. Deixou claro que explorou 0 comprimento das crianças e que não trabalharam com a noção de peso (massa corpórea). Nesse momento, afixamos o painel na parede. Jane começou a explicar como mediram as crianças utilizando uma régua que há na sala e trabalharam com eles a questão do tamanho no meio do ano. Agora em novembro, "que está quase chegando as férias", disse, resolveu medi-las novamente. Em junho, utilizaram um barbante branco para a primeira medição e um outro barbante vermelho para a segunda medição, em novembro. Afixaram uma foto de cada criança e o registro numérico do comprimento de cada uma delas, conforme Figura 1.

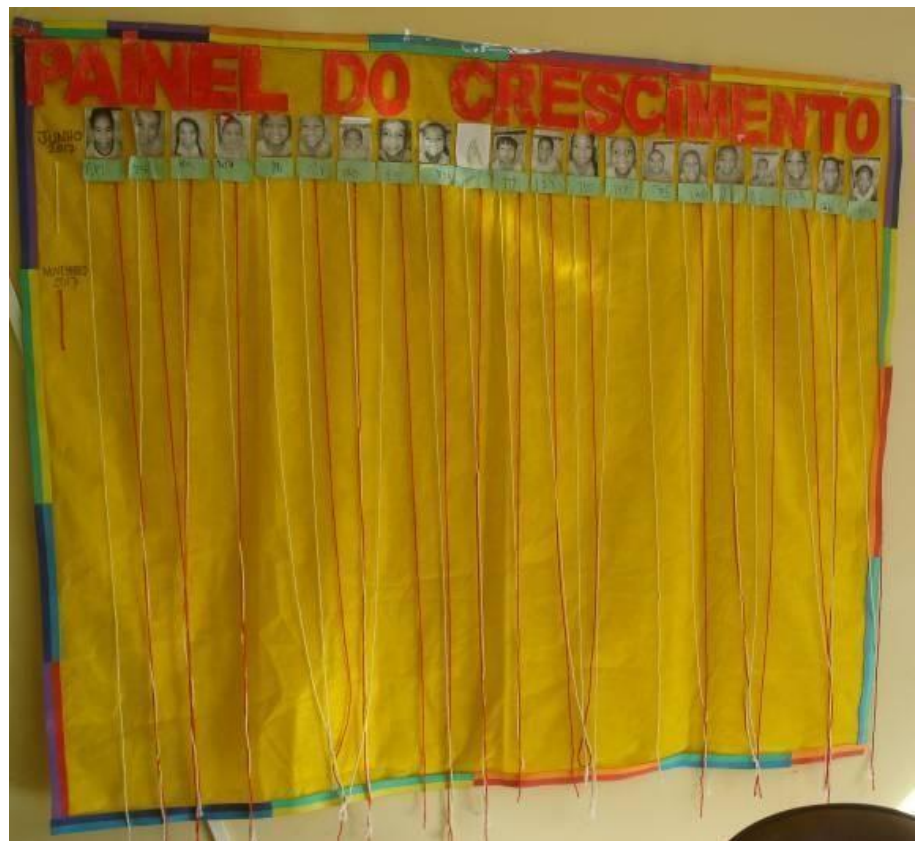

Figura 1: Fotografia do Painel do crescimento (Acervo da Pesquisa)

Durante as reflexões sobre a experiência, as participantes foram discutindo, conforme as transcrições:

Jane: A princípio, quando estava só essa cordinha aqui (apontando para o barbante branco), esse painel ficava lá e eles (crianças) nem se importavam muito não. Como se ele estivesse apagado! Aí quando a gente foi para o início de novembro e até começou a conversa pelo grupo, a gente fez o mês de novembro com uma cordinha vermelha... Aí eles ficaram empolgadíssimos e começaram a falar assim: "Nossa tia, eu cresci tanto!" Porque ainda fala tia lá, né? Uns falavam assim: "Nossa, o Davi não cresceu quase nada!" Porque o Davi é pequenininho. "Cresceu, cresceu sim... Olha aqui a diferença aqui ó!" (Jane mostra as duas medições do Davi: barbante branco e vermelho, comparando-os). (...)

Todos cresceram entre três centímetros. "Quantos cresceram três centímetros?" (mostrando o tamanho no barbante) A gente não fez essa tabela, eu pensei: "Poxa, a gente podia ter feito o gráfico, né?" "Quantos cresceram um centímetro? Dois centímetros?" À medida que a gente começa 


\begin{abstract}
a fazer uma coisa, parece que vai despertando para outras! A princípio, quando a minha coordenadora me pediu para fazer esse painel, eu pensei: "Gente, pra quê que a gente vai fazer isso? Qual o objetivo?" Isso não estava tão claro. Hoje, acho que isso está mais claro, até compartilhei com minhas colegas também lá da creche... E a gente pode estar aprofundando um pouco mais nisso e de uma forma divertida com as crianças. Eu posso voltar e fazer um gráfico com eles... É mais ou menos assim que a gente está trabalhando medidas.

Rosemary: Se você fizer gráfico dá pra saber quem é o mais alto e o mais baixo...

Pesquisadora: O painel já representa um gráfico!

Jane: A gente queria que eles percebessem isso! Olhando por aqui, vão observar e vão falar (...) Isso (apontando para o painel) trabalha bem a observação deles, porque eles não percebiam esse quadro. Foi só quando a gente colocou o vermelho que eles perceberam que era o novo tamanho deles.
\end{abstract}

(Arquivo de vídeo das pesquisadoras, intervalo 0:07:19 a 0:10:12)

A produção de conhecimento realizada pela professora Jane fica explícita em seu relato, principalmente, quando diz "a gente começa a fazer uma coisa, parece que vai despertando para outras!" Ela mobiliza um saber utilizado anteriormente e ressignifica e elabora conhecimento sobre a sua prática. Discutimos ainda algumas possibilidades de construção de gráficos, como 0 exemplo do Painel do crescimento. Abordamos também outras vivências para exploração da fita métrica e da régua na Educação Infantil. Jane disse que sugeriu à sua coordenadora pedagógica trabalhar com as crianças 0 que nos faz crescer, buscando um projeto transdisciplinar, explorando também a variação da massa de cada criança. Finalizamos esse momento do relato com as professoras presentes agradecendo, elogiando bastante e traçando comparações entre as medidas das crianças entre os meses de junho e novembro.

Enquanto pesquisadora ${ }^{7}$, não havia planejado fazer esse relato, apesar do tema do encontro ser Grandezas e Medidas ${ }^{8}$. Decidi apresentá-lo no instante em que o grupo começou a se dispersar falando sobre relatórios na Educação Infantil.

Relatei que levei uma balança digital para a instituição, pesei todas as crianças da turma e fizemos um registro com desenhos e escrita numérica do peso. Como a maioria das crianças não sabia escrever números maiores de dez, meu objetivo era trabalhar com estimativa. Para isso, antes de pesar, propus às crianças que se agrupassem, dando as mãos ao colega que elas

\footnotetext{
${ }^{7}$ Apenas uma das pesquisadoras estava presente nos encontros do trabalho de campo.

8 De acordo com o documento Referencial Curricular Nacional para a Educação Infantil, em relação ao bloco "Grandezas e Medidas", envolve: "Exploração de diferentes procedimentos para comparar grandezas; Introdução às noções de medida de [...] peso, [...] pela utilização de unidades convencionais e não convencionais;"' (BRASIL, 1998, p. 225).
} 
achavam que tinha o mesmo peso que o seu, organizando-se em duplas.

Em seguida, conversei um pouco com as crianças sobre o desenho e registro. Fizemos uma exposição dos registros, deixando a balança exposta também. Na figura 2, apresentamos 0 desenho realizado pela dupla Analice e Humberto que estimaram ter o mesmo peso.

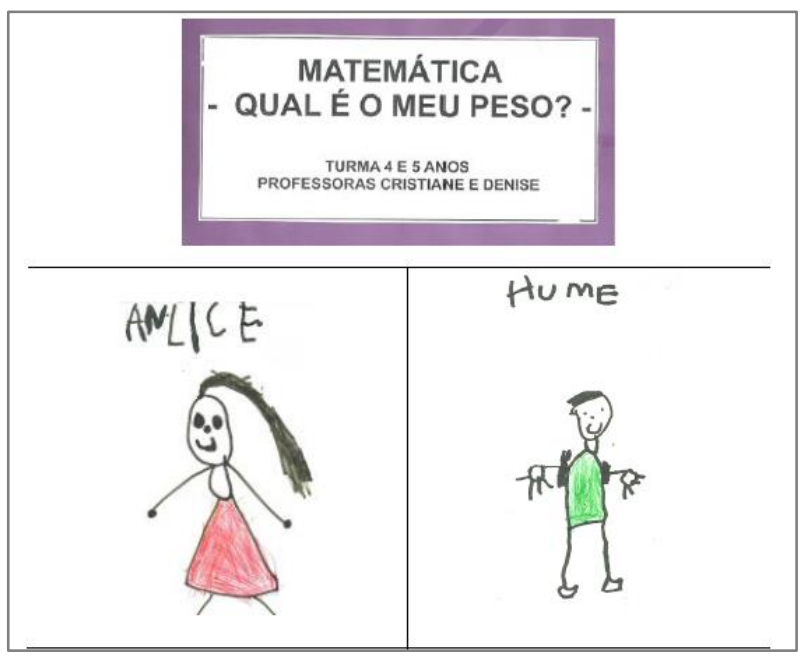

Figura 2: Painel de desenhos infantis (Dados da Pesquisa)

Encerrando esse momento dos relatos, entreguei páginas de um trecho retirado do livro De professora para professora: conversas sobre iniciação Matemática, organizado em 2008 por Regina Célia Grando, Luana Toricelli e Adair Mendes Nacarato. Dividimos as páginas 37 a 40 referentes a um relato e cada uma leu uma página em voz alta. Após a leitura do relato Sonhando com o jogo de gude..., feito pela professora Daniela Leardini Rodrigues em uma turma de vinte crianças de cinco anos esclarecemos algumas dúvidas sobre o desenvolvimento do jogo.

Após lermos o registro da professora, fizemos novamente a leitura do registro das crianças, pois o grupo não compreendeu como a brincadeira aconteceu. Ilustramos para compreendermos melhor, levantamos dúvidas e discutimos variações e possibilidades do jogo, pois cada criança recebeu três bolinhas de gude: duas para serem apostadas e uma que era a "tecadeira". Abordamos ainda sobre a dificuldade de elaborar e propor brincadeiras em uma turma com muitas crianças. Reafirmei e estimulei para que o grupo registrasse nossas experiências e discussões no caderno de memórias para elaborarmos um livro sobre como foi essa vivência de formação em grupo de estudos.

Nesse instante, fizemos uma pausa para o lanche e muitas conversas informais sobre 0 decorrer da semana, problematizando inclusive o número de crianças matriculadas em cada turma. Voltando da pausa, foi entregue um texto do mesmo livro utilizado no encontro anterior, 
Educação Infantil e percepção Matemática (LORENZATO, 2011) e lemos um trecho retirado do capítulo 8: 0 senso de medida ou diferentes interpretações da medição (p. 53 a 56). 0 autor aborda como cotidianamente as crianças convivem com noções que antecedem 0 ato de medir e são fundamentais à construção do conceito de medida: "O conceito de medida é abrangente, pois pode se referir a distância, superfície, espaço, massa, calor (temperatura), movimento (velocidade) e duração (tempo). Trata-se também de um conceito complexo, uma vez que cada um desses itens possui variações" (LORENZATO, 2011, p. 53).

Lemos as variações citadas por Lorenzato (2011) e discutimos uma a uma tentando exemplificá-las no cotidiano das instituições de Educação Infantil. Mesmo com a leitura e discussão coletiva, concordamos com a conclusão autor quando afirma que a medição é realmente um processo amplo e complexo; por isso seu ensino deve ser planejado cuidadosamente.

Após a leitura e discussão do texto, apresentei diversos materiais manipulativos — fita de cetim, fita métrica, régua, caixa vazia, caixa cheia, figuras planas recortadas em papelão etc. como "ferramentas" para tentar nos auxiliarem na análise do campo conceitual da medida no que se refere, principalmente, às grandezas e ao seu vocabulário:

- distância: largo, estreito, maior, menor, largura, altura;

- espaço: grosso, fino, gordo, magro, alto, baixo, grande, pequeno, maior, menor;

- massa: pesado, leve;

- calor: quente, frio, gelado

- movimento: rápido, lento, devagar, depressa;

- duração: ontem, hoje, amanhã, antes, depois, agora. (LORENZATO, 2011, p. 55)

Ainda dentro da discussão do trecho lido e da análise de propostas de atividades com materiais manipulativos, o grupo foi ampliando a participação, observando os objetos e fazendo levantamentos de possibilidades de exploração do conceito de superfície:

Adriana: Se a criança não for trabalhada com várias coisas (referindo-se à exploração de conceitos e materiais manipulativos), quando chegar na hora de ver o "metro pequenininho", ela não vai compreender que aquele "metro pequenininho" está representando o "grande". São as coisas que são trabalhadas antes, anteriores!

Rosemary: Ela precisa de um entendimento anterior.

(Arquivo de vídeo das pesquisadoras intervalo 01:52:00 a 01:52:30).

A professora Adriana estava se referindo ao trabalho com medidas no Ensino 
Fundamental. Frequentemente, é possível ver atividades visuais de medição em livros didáticos que reduzem o metro para uma escala em centímetro. Muitas atividades envolvendo medidas de superfície fazem essa escolha didática, exigindo a abstração que, na maioria das vezes, 0 estudante do Ensino Fundamental não possui. Conforme Lorenzato (2011, p. 56),

pelo exposto, verifica-se que é longo e complexo o processo de construção do conceito de medida, que começa com a comparação visual e direta entre dois objetos, passa pela conveniência da utilização de unidade de medida e finaliza na abstração de um número, que expressa sempre uma relação. (

Adriana relatou também que sua turma ganhou umas caixas com Tangran e ela estava muito preocupada em como utilizá-lo em suas práticas pedagógicas. Primeiramente, estava preocupada em como organizar o material com as crianças, pois as peças poderiam sumir durante a atividade. Conversamos sobre como é mais importante que as crianças brinquem e explorem os atributos das peças, fazendo figuras livremente manipulando todas ou algumas peças do Tangran. O assunto continuou, pois Adriana mostrou outra preocupação, levantando um tema que poderia ser proposto para estudo no quinto encontro9:

Adriana: Eu sei que é legal trabalhar com o Tangran! Aí... Pode ser até um assunto! Mas eu não sei direito assim o objetivo, como trabalhar, o quê que esse trabalho com o Tangran, leva a criança a quê? Criatividade? Na Matemática, eu não sei o objetivo de trabalhar com o Tangran, se é importante mesmo? Eu estou falando sincera, eu vejo as pessoas falando muito do Tangran, mas eu não "peguei" para estudar o objetivo, a importância.

(Arquivo de vídeo da pesquisadora, intervalo 02:01:57 a 02:02:37)

O grupo conversou sobre as possibilidades e os limites com o Tangran, buscando sugestões e esclarecimentos para Adriana. Perguntei se alguém havia usado o Tangran na Educação Infantil, mas ninguém respondeu. Também abordamos o uso e propostas de atividades com blocos lógicos, esses são mais utilizados, mas também, sem intencionalidade pedagógica.

Novamente identificamos características apresentadas pelas professoras como constituintes de um grupo colaborativo, dando destaque aqui à espontaneidade para levantamento de temas e situações problemáticas nas práticas pedagógicas.

Em seguida, retomamos a leitura do texto que abordava os conceitos de massa, calor, movimento e duração (LORENZATO, 2011, p. 54). Perguntei o que elas acharam e a resposta foi que "esse assunto é bem complexo". Como percebi que estavam muito caladas, perguntei sobre

\footnotetext{
${ }^{9}$ Exemplo de uma demanda do grupo de professora participantes que serviu para a organização do encontro seguinte.
} 
o que fazemos hoje nas instituições de Educação Infantil dentro desses conceitos? "Há coisas mais fáceis de trabalhar?"

Rosemary respondeu que "quando parte da realidade da criança, é mais fácil". Depois dessa resposta, conversamos brevemente sobre exploração de receitas, como preparação de sucos e bolos em sala de aula. Insisti perguntando que outras práticas abordam a exploração dos conceitos de medida, mas o grupo estava muito silencioso. Jane pegou uma régua que estava sobre a mesa e timidamente disse que precisava trabalhar mais com aquele instrumento de medida.

Encerramos o quarto encontro, conversando sobre os instrumentos de medição como balança, relógio, velocímetro, régua e termômetro, tais como relatados por Lorenzato (2011) e sobre o papel do professor despertando o senso de medida nas crianças ao oportunizar situações desafiadoras para resolução de problemas.

Consideramos que foi importante para o grupo ouvir os relatos da professora Jane a respeito do Painel do Crescimento, assim como as análises que foram apresentadas pelas demais participantes ao longo dos encontros. A professoa Jane também se propõs a registrar suas memórias sobre o que relatou. Identificamos a mesma postura de rever, refletir e associar outros conhecimentos às práticas pedagógicas, ou seja, as reflexões sobre o eixo saber-fazer. Acreditamos que essas e outras pequenas atitudes estão inseridas em vivências cotidianas dos professores, ressignificadas quando possuem intencionalidade e modificam os fazeres do cotidianodascrianças.

\section{Considerações}

Ao finalizarmos os encontros compreendemos e avaliamos que o grupo de estudos formado por professoras da Educação Infantil e a pesquisadora se constituiu como espaço formativo permitindo as descrições de situações problemáticas envolvendo o conhecimento matemático. Aos poucos, identificamos indícios de que os saberes e conhecimentos das professoras foram mobilizados, reconhecidos e ressignificados durante a manutenção do grupo.

Destacamos ainda que a própria experiência de participação de uma formação continuada em um grupo de estudos em contexto colaborativo, que propusemos na pesquisa, alterou concepções sobre docência e formação continuada das participantes e principalmente a nossa. 
Ouvir a fala de cada professora participante trouxe outro significado para as análises dos encontros, o que constituiu parte do planejamento metodológico deste estudo.

A partir das narrativas apresentadas nos encontros do grupo de estudos, podemos concluir que as instituições têm se tornado lugar escasso de espaços de discussão e seus atores precisam compreender que as discussões são essenciais para o desenvolvimento profissional do professor, incentivando a formação de um grupo colaborativo. Ousamos dizer que o grupo precisa ter a perspectiva interacionista para satisfazer necessidades emocionais que abrangem o eixo serpensar e as intelectuais saber-fazer dos participantes. A partir das narrativas das professoras participantes, os momentos vividos foram registrados e culminaram na produção de um livro (STEHLING e CONTI 2019). Os relatos orais e os registros das professoras expressaram indícios de mudanças em suas práticas, pois foram encontradas ações intencionais, compromisso consciente com as próprias necessidades formativas e busca ativa na construção de uma formação compartilhada com seus colegas de profissão, também participantes do grupo deestudos.

Em relação aos objetivos propostos neste estudo, analisamos que os saberes e conhecimentos matemáticos e metodológicos foram mobilizados, com destaque aqui para Grandezas e Medidas, bem como outras aprendizagens durante a constituição e manutenção do grupo de estudos. Escutamos e registramos várias narrativas enfocando o saber e o fazer docente envolvendo problematizações e discussões na busca de soluções e reflexões, possibilitado em contexto colaborativo de estudos.

Vários conhecimentos sobre a prática foram descritos pelas participantes da pesquisa, como, por exemplo, procedimentos para comparar grandezas, noções de medida de comprimento (painel do crescimento), peso (Qual o meu peso?), e outros discutidos teoricamente por meio de referencial teórico (LORENZATO, 2011). Houve também o início ou a retomada da discussão em outros encontros do grupo como, por exemplo, medida de tempo (segundo encontro); outras alternativas metodológicas, como jogos e resolução de problemas, que analisamos que refletem um conhecimento pedagógico de conteúdo aprendido na formação inicial das professoras.

Sugerimos que a educação e os gestores públicos deem mais atenção para que a situação da sujeição seja invertida em direção à emancipação e à nova postura crítica dos sujeitos. Uma opção seria a reflexão sobre o uso dos espaços coletivos de discussão. 


\section{Referências}

AZEVEDO, Priscila Domingues. O conhecimento matemático na Educação Infantil: o movimento de um grupo de professoras em processo de formação continuada. 2012. 241f. Tese (Doutorado em Educação) - Centro de Educação e Ciências Humanas. Universidade Federal de São Carlos. São Carlos.

BOGDAN, Roberto C.; BIKLEN, Sari Knopp. Investigação qualitativa em Educação: uma introdução à teoria e aos métodos. Tradução de Maria João Alvarez, Sara Bahia dos Santos, Telmo Mourinho Baptista. Porto: Porto Editora, 1994.

BRASIL. Ministério da Educação. Conselho Nacional de Educação. Resolução CNE/CP n. 1, de 15 de maio de 2006. Institui Diretrizes Curriculares Nacionais para o curso de graduação em Pedagogia, licenciatura. Brasília: Diário Oficial da União, 18 dez. 2006.

BRASIL. Ministério da Educação. Secretaria de Educação Básica. Base Nacional Comum Curricular: Educação Infantil e Ensino Fundamental. Brasília: MEC/SEB, 2017.

BRASIL. Ministério da Educação. Secretaria de Educação Fundamental. Referencial Curricular Nacional para a Educação Infantil. Brasília: MEC/SEF, 1998.

COCHRAN-SMITH, Marilyn; LYTLE, Susan L. Relationships of knowledge and practice: teacher learning in communities. Review of Research in Education, Washington, n. 24, p. 249-305, 1999.

CONTI, Keli Cristina. Desenvolvimento profissional de professores em contextos colaborativos em práticas de letramento estatístico. 2015. 273f. Tese (Doutorado em Educação) — Faculdade de Educação. Universidade Estadual de Campinas. Campinas.

DAY, Christopher. Desenvolvimento profissional de professores: os desafios da aprendizagem permanente. Tradução de Maria Assunção Flores. Porto: Porto Editora, 2001.

FIORENTINI, Dario. Pesquisar práticas colaborativas ou pesquisar colaborativamente? In: BORBA, Marcelo de Carvalho; ARAÚJO, Jussara de Loiola. (Org.). Pesquisa Qualitativa em Educação Matemática. 2 ed. Belo Horizonte, Autêntica: 2006, p. 49-78.

FIORENTINI, Dario; LORENZATO, Sérgio. Investigação em Educação Matemática: percursos teóricos e metodológicos. 3 ed. Campinas: Autores Associados, 2012.

GAUTHIER, Clermont; MARTINEAU, Stéphane; DESBIENS, Jean-François; MALO, Annie; SIMARD, Denis. Por uma teoria da Pedagogia: pesquisas contemporâneas sobre o saber docente. Tradução de Francisco Pereira de Lima. 2. ed. ljuí: Editora Unijuí, 2006.

IMBERNÓN, Francisco. Formação continuada de professores. Tradução de Sandra Trabucco Valenzuela. Porto Alegre: Artmed, 2010.

LEITE, Yoshie Ussami Ferrari. Os cursos de Pedagogia formam professores dos Anos Iniciais do Ensino Fundamental? In: DALBEN, Angela; DINIZ, Julio; LEAL, Leiva; SANTOS, Lucional. (Org). Convergências e tensões no campo da formação e do trabalho docente. Belo Horizonte: Autêntica, 2010, p. 569-587. 
LORENZATO, Sérgio. Educação Infantil e percepção matemática. 3. ed. Campinas: Autores Associados, 2011.

NACARATO, Adair Mendes. Narrar a experiência docente... Um processo de (auto)formação. In: GRANDO, Regina Célia; TORICELLI, Luana; NACARATO, Adair Mendes. (Org.) De professora para professora: conversas sobre iniciAção matemática. São Carlos: Pedro \& João Editores, 2008, p. 143-159.

STEHLING, Denise França. Saberes e conhecimentos matemáticos na Educação Infantil: formação continuada de professores em um grupo de estudos. 2018. 147f. Dissertação (Mestrado em Educação e Docência) - Faculdade de Educação. Universidade Federal de Minas Gerais. Belo Horizonte.

STEHLING, Denise França; CONTI, Keli Cristina. A arte da palavra: ressignificando o vivido. Belo Horizonte: FaE/UFMG, 2019.

TARDIF, Maurice. Saberes docentes e formação profissional. Tradução de Francisco Pereira. 5. ed. Petrópolis: Vozes, 2002. 